Review

\title{
Dimeric Surfactants: Promising Ingredients of Cosmetics and Toiletries
}

\section{Naveen Kumar and Rashmi Tyagi *}

Department of Chemical Engineering, Jaypee University of Engineering \& Technology, Guna, Madhya Pradesh 473226, India; E-Mail: naveenharsana@gmail.com

* Author to whom correspondence should be addressed; E-Mail: rashmi.tyagi@juet.ac.in; Tel.: +91-9425798395.

Received: 29 August 2013; in revised form: 30 October 2013 / Accepted: 31 October 2013 / Published: 21 November 2013

\begin{abstract}
Surfactants are an essential ingredient for cosmetic, toiletries and personal care products for enhancing their performance. Dimeric surfactants demonstrate superiority compared to conventional surfactants in all areas of application. Dimeric surfactants are extremely promising for utilization in various cosmetic formulations viz. shampoo, lotions, creams, conditioners etc. These surfactants possess extremely unique surface properties viz. lower surface tension, unique micellization, low critical micelle concentration (CMC) and antimicrobial activity, higher solubilization etc. Dimerics enhance the performances of cosmetics in an extraordinary manner and provide eco-friendly preparations for human epidermis.
\end{abstract}

Keywords: dimeric surfactants; critical micelle concentration; surface activity; cosmetics

\section{Introduction}

The worldwide market for cosmetics surfactants was evaluated to be around US $\$ 10.5$ billion in 2012. This massive multi-million dollar market is captured by cosmetics and personal care products prevalently. As a result of improved living standards and continuing cultural driving forces, this market continues to grow. Mainly, these products have been made from fats and oils, which generally are perceived to have the advantage of occurring naturally in the human body but display fewer problems in terms of toxicity, allergenicity etc. [1]. Modern surfactants have made it possible for us to attain the same or better results. Dimeric surfactants attracted attention for the manufacturing of 
cosmetics, cleaning agents, lotion and personal care products to attain better results in term of their mildness, soft feeling and absence of dermal irritation. Their mildness, foaming ability and good water solubility make them attractive ingredients in various formulations of body cleanser and facial cleanser. Nowadays, they are employed in assorted types of cosmetics and cleansing formulations but, furthermore, are verifying their utilities in textile and dyeing, genetics science, pharmaceuticals and paints industries [2-6]. Dimerics are selected for these requisitions because of their versatility and low cost. In addition, they are also used in the preparations of shampoos and conditioning agents. This paper gives a brief sketch on the surface properties and potential applications of dimeric surfactants in the field of cosmetics. Systematic representation of dimeric surfactants has been shown in Figure 1.

Figure 1. Systematic representation of dimeric surfactants.

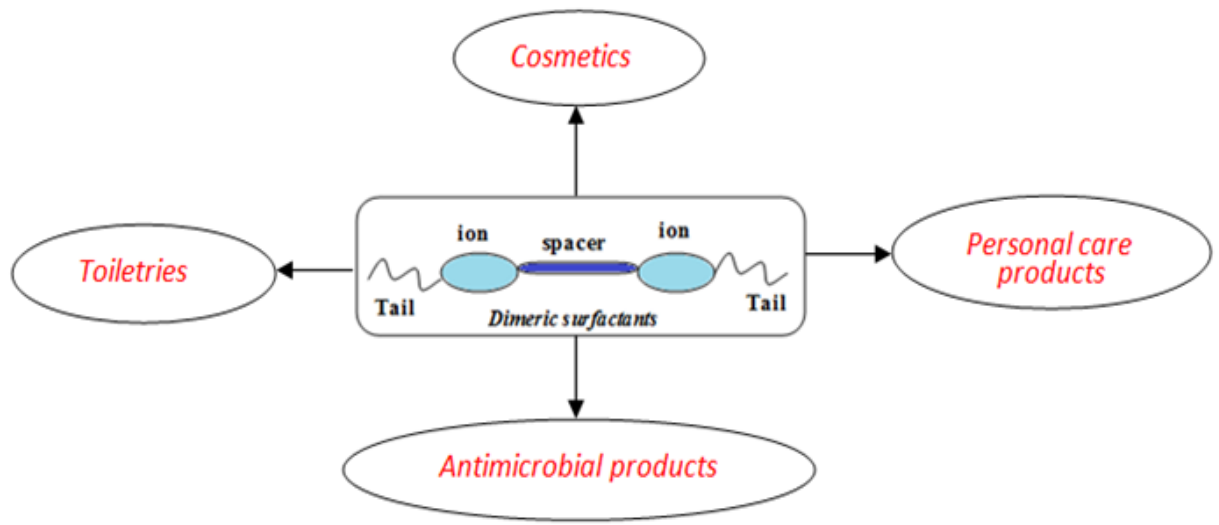

\section{Physico-Chemical Characteristics}

In cosmetics, surfactants are basically utilized as wetting agents, cleaning agent, conditioners, foaming agents, solubilizers, and thickeners for moisturizers. Apart from these actions, they are additionally utilized for making a wide variety of dispersed systems. The following physico-chemical aspects of dimeric surfactants are successively reported.

\subsection{Surface Activity and Micellization}

The critical micelle concentration (CMC) is defined as the concentration of surface active agents above which surfactant particles sharply assemble into aggregates called micelles [1]. The CMC values are important in virtually all of the process industry's surfactant applications, viz. formulation of cosmetics and personal care products, emulsion polymerization and drug delivery systems. The CMC is helpful as it reveals the propensity of surfactants to assemble in water. Wattebled and Laschewsky [7] reported the surface active behaviors of EDTA based dimeric surfactants. They determined the CMC of synthesized dimeric at $\mathrm{pH} 7-8$ and $\mathrm{pH} 12$ and found the $\mathrm{CMC}$ to be $0.02 \mathrm{mmol} / \mathrm{L}$ for neutral $\mathrm{pH}$ range and $0.03 \mathrm{mmol} / \mathrm{L}$ for alkaline $\mathrm{pH}$ range. The $\mathrm{CMC}$ of dimerics are typically one order of magnitude lower than the corresponding monomeric surfactant. The CMC of anionic dimeric surfactants also decrease with increasing spacer length [8]. Bai et al. [9] adduce that micellization of dimeric surfactants and compared the result with monomeric surfactants, which displayed CMC values significantly lower than monomeric surfactants. Lim et al. [10] also found that cationic dimeric surfactants having 
hydroxyl groups revealed minimal surface tension and CMC. Kenichi Sakai et al. [11] reported static surface tension of aqueous solution of 9,10-dihydroxyoctadecanoic acid alkyl esters (CC-9,9-Esn) as a function of their concentrations. These measurements were presented at $\mathrm{pH} 9$ in the presence of $10 \mathrm{mmol} \mathrm{dm}^{-3} \mathrm{NaCl}$. In the area of low surfactant concentrations, the surface tension declines swiftly with increasing concentration and obtains a break point. The surfactant concentration corresponding to this break point is assumed to be the CMC of surfactants.

\subsection{Solubilization Capacity and Krafft Point}

Solubilization is an important phenomenon required in various cosmetic formulations. Addition of dimerics in cosmetic viz. creams, gels, lotions and ointments work as a colloidal materials and enhanced solubilization of all ingredients adequately. Dimeric surfactants are superior solubilizers because of their very low CMC values. Many organic compounds that are normally insoluble in water, or only lightly soluble, dissolve to a greater extent in the presence of micellar surfactant. The increased solubility is called solubilization. Dam et al. [12] reported dimeric surfactants, alkanediyl- $\alpha, \omega-$ bis(dimethylalkylammonium bromide), which have been found to have a larger solubilizing capacity for this compound than for the conventional monomeric surfactants. The disposition of the dimeric micelles is considerably more soluble in oil as compared to conventional surfactants. Recently, Wattebled and Laschewsky [7] studied solubilization capacity of synthesized dimerics with conventional analogs and found that dimerics have higher solubilization capability as compared to sodium laurate.

Krafft point temperature is the characteristic temperature at which the solubility of surfactant becomes equal to critical micelle concentration. For surfactant to be considered soluble, their Krafft point temperature has to be below room temperature [13]. The Krafft points of several dimeric surfactants have been reported to be well below $0{ }^{\circ} \mathrm{C}$ [14-20]. This low Krafft point permits the use of this compound in cold water. These properties are usually utilized to assess surfactant performance and are important for applications like cleaning and stabilization of dispersed systems.

\subsection{Foaming and Froth Ability}

For the production of cosmetics, personal care and toiletries products, the foam performance of hair and body care products have to be optimized so the consumer will experience a most affirmative and sensorial impression over the product. Surfactants are very famous ingredients for the manufacturing of toothpaste; in toothpaste these compounds are used to create foam while teeth are brushed. This foam provides an enjoyable sensation. Surfactants also help to remove material dislodged by the toothbrush, and it may have minor effects on plaque accumulation. The foam performances of the products according to the specific requisition during the application play a foremost role. Parameters like surface tension, surface viscosity and surface elasticity are amenable for the adjustment of the required foam properties of the system [21]. Rosen et al. [22,23] have found that dimeric surfactants have a superior soap-dispensing efficiency. These surfactants, on account of their low sensitivity to $\mathrm{Ca}^{2+}$ and $\mathrm{Mg}^{2+}$, could be utilized in cleaning and other industrial processes, where presence of hard water makes the conventional surfactants inefficacious. The initial foam height and foam stability of dimeric surfactants are better than their conventional analogs. Anionic dimeric surfactants 
having carboxylate head groups of structure $\left(\mathrm{C}_{11} \mathrm{H}_{23}\right)_{2} \mathrm{C}(\mathrm{OCHCOONa})_{2}$, are observed to foam more than their conventional surfactants as $\mathrm{C}_{11} \mathrm{H}_{23} \mathrm{COONa}$ [24]. Fujikura et al. [25] claimed dicarboxylate anionic dimeric of structures $\left[\mathrm{C}_{10} \mathrm{H}_{21} \mathrm{~N}\left(\mathrm{COCH}_{2} \mathrm{CH}_{2} \mathrm{COO} \mathrm{Na}^{+}\right) \mathrm{CH}_{2}\right]_{2} \mathrm{CHOH}$, which display elevated foaming behavior at $0.1 \%$ concentration of the sodium laurate. Pinazo et al. [26] reported arginine based cationic dimeric surfactants; these dimerics showed greater foam stability. These dimeric are almost 20 times more dexterous foam stabilizers than cationic monomeric surfactant.

\subsection{Emulsifying Properties}

Emulsifiers are valuable class of surfactants for cosmetics and personal care. These are very vital to make creams and various lotions in cosmetic industries. Numerous cosmetic commodities are designed to add oily constituents to the skin and hair. These components commonly cannot be used directly because they have obnoxious features in their concentrated nature. Hence, emulsions using surfactants are vital in cosmetics based formulation. Emulsifiers or surfactants are employed to assist in mixing and balancing the mixtures. J. Nowicki [27] reported that asymmetrical nonionic dimeric surfactants show good emulsifying and phase properties. Qun Xu et al. [28] also found that emulsifying power of dimeric surfactant is much better than conventional single tailed surfactants. Diquaternary ammonium dimerics prepared by Dreja and Tieke [29] have been found to be much better than conventional surfactants in solubilizing styrene in water.

\section{Uses of Dimeric Surfactants in Cosmetics and Personal Care Products}

Dimeric surfactants are usually applied for the manufacture of cosmetics, shampoos, body lotions, and personal care products due to their pulpy effect, mildness, and absence of skin irritation. The various possible applications of dimeric surfactants in cosmetics and personal care are discussed here under.

\subsection{In Cosmetic Formulations}

Cosmetic formulations are reliant on modern formulation methods for emulsions, especially for storage properties [30]. These products are generally based on emulsions of oil-in water $(\mathrm{o} / \mathrm{w})$. The phase inversion temperatures of emulsion and microemulsion are described by fine droplet dimensions which are highly steady; microemulsions are helpful for conceiving a clear formulation of o/w and, furthermore, emerge to create a less irritating product. This formulation method has found use in deodorant emulsion preparation [31]. The durability and viscosity of the emulsion depend heavily on the structure of the emulsion. Kwetkat [32] described that the dimeric surfactant viz. sodium dicocoylethylenediamine PEG-15 could be utilized for o/w emulsion for the end use of cosmetics and personal care products for face lotion, skin care, hair care, sun protection, and skin moisturizing. This dimeric surfactant is traded in a combination with cosurfactants under the trade mark Ceralution. Ceralution $\mathrm{H}$ is a suitable blend of the dimeric surfactant, behenyl alcohol, glyceryl stearate, and glyceryl citrate. It can be applied to make a category of stable dispersions of micropigments like titanium dioxide in water, as used for the preparation of sunburn cream. Ceralution $\mathrm{F}$ is a mixture of lauroyl lactylate and sodium dicocoylethylenediamine PEG-15 sulfate, which detract the irritating effect of alkylethersulfate. It is a congenial personal care product for skin care which keeps the skin 
soft and supple throughout winter. A patent [33] reported dimeric surfactants having a high scale of solid fatty substance. These surfactants show the cosmetic composition of o/w emulsion type proposed for keratin components, specifically the skin, hair, lips and nails. Textures affluent in solid fatty substances with high viscosities are especially beneficial for skin health management. In fact, they are especially prescribed for dry skin. Villa et al., [34] adduced dimeric surfactants, disodium 2,3-dialkyl-1,2,3,4-butanetetracarboxylates, can be applied as new winsome ingredients in cosmetics, toiletries and personal care products.

\subsection{Skin and Eye Irritation}

Various anionic, cationic and amphoteric dimeric surfactants have been described to inhibit eye and skin irritation. The betaine type dimeric surfactants were less irritating to the eyes than its single chain analog [35]. Anionic dimeric, for example $\left[\mathrm{C}_{11} \mathrm{H}_{23} \mathrm{CONHCH}_{2} \mathrm{CH}_{2} \mathrm{NCH}_{2} \mathrm{CH}_{2} \mathrm{COO}^{-} \mathrm{Na}^{+}\right]_{2} \mathrm{CH}_{2} \mathrm{CH}_{2}$, revealed to be mild for skin [36]. Puchta et al., [37] found that dicationic dimeric of structure $\left[\mathrm{C}_{12} \mathrm{H}_{25} \mathrm{~N}^{+}\left(\mathrm{CH}_{3}\right)_{2} \mathrm{CH}_{2} \mathrm{CONH}\right]_{2} Y$, where $Y$ is $\left(\mathrm{CH}_{2}\right)_{4}$ was not irritating at a concentration of $<0.5 \%$. Sulfoesters type anionic dimeric tested on human arms by protein denaturation are thought to be elevated to single chain sulfomonoester. This kind of dimeric surfactants had demonstrated lesser protein denaturation by a variable of $10 \%$ and $5 \%$ solution, and use on human arms for five days resulted in no skin scar or redness [38]. Methylene bis sulfate of structure $\left[\mathrm{C}_{8} \mathrm{H}_{17} \mathrm{C}_{3} \mathrm{H}_{6} \mathrm{O}\left(\mathrm{C}_{2} \mathrm{H}_{4} \mathrm{O}\right)_{7} \mathrm{O}_{3} \mathrm{Na}\right]_{2} \mathrm{CH}_{2}$ was tested as a mild surfactant [39], while one patent [25] claimed that sulfated dimeric surfactants tested on the abdominal region of guinea pigs exhibited no irritancy. Deodorants are applied for personal hygiene to get rid of body rot, which happens due to the microorganism decomposition of sweat, common beneath the arm zone. Smell can be controlled by employing a formulation which inhibits the secretion of sweat or its putrefaction. Mainly active compounds are citric acid or aluminum chlorohydrate; however, their preventative power is for a confined time span and is dependent on the way in which sweat is secreted. It has been found that formulations containing a dimeric surfactants viz. alcoholethersulfate, dimeric alcoholsulfate, or trimeric alcohol-trisethersulfate [40], aluminum chlorohydrate, an esterase resistor, an antiseptic agent, and a bacteriostatic agent are extremely efficacious. These surfactants also enhance the reconcilability between skin and cosmetics and inhibit the activity of esterolytic enzymes. In addition to this, a very minor amount are utilized in cosmetic formulations. They can also be employed for manufacturing hair lotions, hair shampoos, cream gels or lotions and bubble baths. The ability of the formulation was displayed by way of its inhibition of esterase within $15 \mathrm{~min}$ with a concentration of $100-6000 \mathrm{mg} / \mathrm{L}$ at $\mathrm{pH}$, as compared with a non-inhibited control. The outcomes revealed a reduction of esterase action from $100 \%$ to $0 \%$ upon the addition of $10-100 \mathrm{mg} / \mathrm{L}$ of dimeric alcoholsulfate, though the activeness remained at $100 \%$ with a concentration of $2000 \mathrm{mg} / \mathrm{L}$ aluminum cholorohydrate without dimeric surfactants [40,41]. The anionic dimeric surfactants, invented by Li and Tracy [42], are exceedingly mild and non-irritating to eyes and skin. They also display high foaming and foam stabilization properties, low toxicity, and superb compatibility with other surfactants like anionic, cationic, and nonionic. These surfactants demonstrate exclusive performance qualities i.e., elevated solubilization of co-ingredients, and the enhanced removal of stains. These competencies make these compounds adaptable for utilization in cosmetics, toiletries and personal care industries. 


\subsection{Hair Care Products}

Gentle detergency, good conditioning and good foaming are the basic principle for formulating a shampoo. Surfactants are the primary ingredients for the formulation of a shampoo, conditioner and other hair care products. Dimeric surfactants have wide applications in hair conditioning and shampoo formulations. The diquaternary ammonium chloride $\left[\mathrm{C}_{18} \mathrm{H}_{37} \mathrm{~N}^{+}\left(\mathrm{CH}_{3}\right)_{2} \mathrm{CH}_{2}\right]_{2} \mathrm{CHOH} 2 \mathrm{Cl}^{-}$was described to display hair conditioning properties preferable to those of stear-alkonium chloride. Rubine dye test illustrated its higher substantivity to hair, as a result of its double charge on the dimeric surfactants [41]. Anionic dimeric surfactant especially advantageous for hair conditioning gels, lotions, non-irritating shampoos viz. baby shampoos, body shampoos, etc. [42].

\subsection{Antimicrobial Activity}

The microbial protections of cosmetic products are an important concern. It is essential to ensuring the steadiness of the products for the whole shelf-life and to avoiding harm to health of the consumers. Dimeric surfactants also could be applied in health care products in various formulations. Dicationic dimeric surfactants $\left[\mathrm{C}_{12} \mathrm{H}_{25} \mathrm{~N}^{+}\left(\mathrm{CH}_{3}\right)_{2} \mathrm{CH}_{2} \mathrm{CONH}\right]_{2} Y_{2} \mathrm{Cl}^{-}$where $Y$ is $\left(\mathrm{CH}_{2}\right)_{4}$ were found to be more suitable against many microorganisms other than hexadecyl trimethyl ammonium bromide (HTAB) [43]. Kim et al. [44] reported the bis-quaternary ammonium compounds with two alkyl chains and two ammonio groups also display good antimicrobial activity. Dicationic m-s-m surfactants with a short spacer demonstrated high antimicrobial activity that is one or two orders of magnitude better than the conventional single-chained disinfectants, viz., benzyldodecyl dimethyl ammonium bromide, 2-ethoxy carbonyl pentadecyl tri-methyl ammonium bromide [45]. Pinazo et al. [46] reported cationic dimeric from cystine amino acid viz. $N$-lauryl- $N, N$-dimethyl glycine cystine dimethyl ester dihydrochloride and $N$-lauryl- $N, N$-dimethyl glycine cystamine dihydrochloride can be applied in cosmetics as well as in pharmaceuticals as powerful antimicrobial agents. Piera et al. [47] developed arginine based dimeric surfactants, these cationic surface active compounds displayed greater antimicrobial activity against a broad spectrum of bacteria, low toxicity and biodegradability. These characteristics and the use of natural raw materials like arginine and fatty acid for their synthesis make them an attractive ingredient as antiseptic and preservative in several cosmetic formulations. Perez et al. [48] have studied the synthesis and evaluation of biocompatible cationic dimeric surfactants. This compound has shown a broad range of antimicrobial properties against microorganisms. In addition, several studies have been found that new type amino acid based dimeric surfactants demonstrate the interesting antimicrobial activity and are used in various cosmetic and pharmaceutical formulations [49,50].

\subsection{Biodegradability}

In addition to microbial protection, consumers now are more aware of the environmental impact of products. The class of amino acid-based dimeric surfactants exhibit advantages such as excellent biocompatibility and wide biological activity, low environmental impact and low potential toxicity over other surfactants. Recently, T. Yoshimura et al. [51] reported amino acid-based anionic dimeric surfactants of structure $2 \mathrm{C}_{n}$ diCys, where $\mathrm{n}$ is an alkyl chain with a length of 10,12 , or 14 carbons and di and Cys represent adipoyl and cysteine, respectively, which have been found to have excellent 
properties such as good water solubility and rapid biodegradability. Dimeric surfactants, viz. bis-sulfonate or bis-carboxylate dimeric surfactants containing $\mathrm{C}=\mathrm{C}$ groups in the lipophilic spacer are cleaved by ozone. Their degradability is much better as compared to conventional surfactants such as linear alkylbenzene sulfate (LAS), sodium dodecyl sulfate (SDS) [52,53]. Tatsumi et al. [54] reported hydrolysable cationic dimeric surfactants, 1,3-bis[(acyloxyalkyl) dimethylammonio]-2-hydroxypropane dichloride that contained oxycarbonyl groups in the lipophile which may be much easily hydrolyzed. These cationic dimeric surfactants demonstrated well biodegradability. L. Perez et al. [55] investigated amino acid-based cationic dimeric surfactants $N^{\alpha}, N^{\omega}$-bis $(\mathrm{N} \alpha$-acylarginine $) \alpha, \omega$-alkylendiamides, describe a class of surfactants with exceptional biocompatibility and biodegradability. They were also found to be effective as antimicrobials.

\subsection{Economical Aspects}

Amphoteric dimeric are influential supple multifunctional surfactants. In spite of the fact they are more expensive than monomeric surfactants, they could be utilized in small quantities in blended surfactants of particular importance. Amphoteric type dimerics, for instance, $\mathrm{N}, \mathrm{N}$-bis(2-lauramidoethyl) ethylenediamine- $\mathrm{N}, \mathrm{N}$-disodium propionate, can be used in various cosmetic products and washing products. This compound is environmentally safe, extremely mild and nonirritating to eyes and skin. The mixture of these dimeric surfactants with monomeric surfactants ameliorates surface activity by one to two orders of magnitude more than a mixture of conventional surfactants [56]. Dimeric surfactants have exceptional mercantile usage potential; their preparation should thus be economical. As a smaller quantity of dimeric is required for a specific use, therefore, cost-efficiency may not be a factor. Expensive dimerics may, however, be used as additives to monomeric surfactants to magnify their surface-active properties. Dow Chemicals, Colgate Palmolive, Hampshire Chemical Corp., and various organizations have contributed a lot to the synthesis of cost-effective dimerics [8]. Colonial Chemical has developed inexpensive anionic dimeric surfactants with mild properties for utilization in personal care products. This dimeric has been produced by linking alkylpolyglucosides with a hydroxypropyl phosphate spacer via a chlorohydroxypropyl phosphate intermediate [57]. Consequently, however, the success of dimeric surfactants actually depends on the potential for chemical makers to produce them for demand, which can reduce the cost that are above that of conventional surfactants, or determine processes that will bring their costs down without detracting from their performance that differentiate them from monomeric surfactants [58].

\section{Conclusions}

Dimerics have an excellent self-association competency at even very little concentrations which makes them an enticing ingredients for cosmetics and personal care products. These brilliant compounds may be applied more broadly, for example, as conditioning agents, antimicrobial agents, solubilizing agents, and in various cosmetics based formulations. The requisition of dimeric surfactants in cosmetics and personal care products has been ruled not solely by their benefits for skin, but also through their emphatic interfacial ability and admirable emulsifying properties. 


\section{Conflicts of Interest}

The authors declare no conflict of interest.

\section{References}

1. Myers, D. Surfactant Science and Technology, 3rd ed.; John Wiley \& Sons, Inc.: Hoboken, NJ, USA, 2006.

2. Choi, T.S.; Shimizu, Y.; Shirai, H.; Hamada, K. Disperse dyeing of polyester fiber using gemini surfactants containing ammonium cations as auxiliaries. Dyes Pigments 2001, 50, 55-65.

3. Tracy, D.J.; Li, R.; Dahanayake, M.; Yang, J. Nonionic Gemini Surfactants. U.S. Patent 6204297, 20 March 2001.

4. Karlsson, L.; Eijk, M.C.; Soderman, O. Compaction of DNA by gemini surfactants: Effects of surfactant architecture. J. Colloid Interface Sci. 2002, 252, 290-296.

5. Holmberg, K. Novel Surfactants Preparation, Applications, and Biodegradability; Marcel Dekker: New York, NY, USA, 2003.

6. Zana, R.; Xia, J. Gemini Surfactants Synthesis, Interfacial and Solution-Phase Behavior, and Applicalions; Marcel Dekker: New York, NY, USA, 2004.

7. Wattebled, L.; Laschewsky, A. New anionic gemini surfactant based on EDTA accessible by convenient synthesis. Colloid Polym. Sci. 2007, 285, 1387-1393.

8. Hait, S.K.; Moulik, S.P. Gemini surfactants: A distinct class of self-assembling molecules. Curr. Sci. 2002, 82, 1101-1111.

9. Bai, G.; Wang, J.; Yan, H.; Li, Z.; Thomas, K. Thermodynamics of molecular self-assembly of cationic gemini and related double chain surfactants in aqueous solution. J. Phys. Chem. B 2001, 105, 3105-3108.

10. Lim, J.C.; Park, J.M.; Park, C.J.; Lee, B.M. Synthesis and surface active properties of a gemini type surfactant linked by a quaternary ammonium group. Colloid Polym. Sci. 2013, 291, 855-866.

11. Sakai, K.; Umemoto, N.; Matsuda, W.; Takamatsu, Y.; Matsumoto, M.; Sakai, H.; Abe, M. Oleic acid-based gemini surfactants with carboxylic acid headgroups. J. Oleo Sci. 2011, 60, 411-417.

12. Dam, T.; Engbert, J.B.F.N.; Karthauser, J.; Karaborni, S.; van Os, N.M. Synthesis, surface properties and oil solubilisation capacity of cationic gemini surfactants. Colloids Surface A: Physicochem. Eng. Asp. 1996, 118, 41-49.

13. De Guertechin, O. Part A: Properties (Surfactant Science). In HandBook of Detergents; Guy, B.; CRC Press: Boca Raton, FL, USA, 1999; Volume 82, p. 132.

14. Laschewsky, A.; Lunkenheimer, K.; Rakotoaly, R.H.; Wattebled, L. Spacer effects in dimeric cationic surfactants. Colloid Polym. Sci. 2005, 283, 469-479.

15. Laschewsky, A.; Wattebled, L.; Arotcarena, M.; Habib-Jiwan, J.L.; Rakotoaly, R.H. Synthesis and properties of new cationic oligomeric surfactants. Langmuir 2005, 21, 7170-7179.

16. Kunieda, H.; Masuda, N.; Tsubone, K. Comparison between phase behavior of anionic dimeric (gemini-type) and monomeric surfactants in water and water-oil. Langmuir 2000, 16, 6438-6444. 
17. Zhu, Y.P.; Masuyama, A.; Okahara, M. Preparation and surface active properties of amphipathic compounds with two sulfate groups and two lipophilic alkyl chains. J. Am. Oil Chem. Soc. 1990, 67, 459-463.

18. Zhu, Y.P.; Masuyama, A.; Okahara, M. Preparation and surface-active properties of new amphipathic compounds with two phosphate groups and two long-chain alkyl groups. J. Am. Oil Chem. Soc. 1991, 68, 268-271.

19. Zhu, Y.P.; Masuyama, A.; Nagata, T.; Okahara, M. Preparation and properties of double-chain surfactants bearing two sulfonate groups. J. Jpn. Oil Chem. Soc. (Yukagaku) 1991, 40, 473-477.

20. Okano, T.; Egawa, N.; Fujiwara, M.; Fukuda, M. $\alpha$-Sulfonated fatty acid esters: II. Solution behavior of $\alpha$-sulfonated fatty acid polyethylene glycol esters. J. Am. Oil Chem. Soc.1996, 73, $31-37$.

21. Engles, T.; von Rybinsiki, W.; Schmiedal, P. Structure and dynamics of surfactant-based foams. Progr. Colloid Polym. Sci. 1998, 111, 117-126.

22. Rosen, M.J.; Zhu, Z.H.; Hua, X.Y. Relationship of structure to properties of surfactants. 16. Linear decyldiphenylether sulfonates. J. Am. Oil Chem. Soc. 1992, 69, 30-33.

23. Rosen, M.J.; Zhu, Z.H. Enhancement of wetting properties of water-insoluble surfactants via solubilization. J. Am. Oil Chem. Soc. 1993, 70, 65-68.

24. Ono, D.; Tanaka, T.; Masuyana, A.; Nakatsuji, Y.; Okahara, M. Preparation and properties of bis(sodium carboxylate) types of cleavable surfactants derived from diethyl tartrate and fatty carbonyl compounds. J. Japan Oil Chem. Soc. (Yakagaku) 1993, 42, 10-16.

25. Fujikura, Y.; Kita, K.; Kitsuki, T.; Maruta, K.; Nakano, A.; Tamura, S.; Tosaka, M.; Uno, M.; Yahagi, K. 2-Hydroxypropanediamine derivative and detergent composition containing the same. U.S. Patent 5714457, 3 February 1998.

26. Pinazo, A.; Perez, L.; Infante, M.R.; Franses, E.I. Relation of foam stability to solution and surface properties of gemini cationic surfactants derived from arginine. Colloids Surfaces A: Phys. Eng. Asp. 2001, 189, 225-235.

27. Janusz, N. Emulsion properties and phase equilibrium and of new asymmetric gemini surfactants consisting of fatty acid esters of polyethoxylated alcohol or phenol. J. Surfact. Deterg. 2010, 13, 195-199.

28. Qun, X.; Liyan, W.; Fenglan, X. Synthesis and properties of dissymmetric gemini surfactants. J. Surfact. Deterg. 2011, 14, 85-90.

29. Dreja, M.; Tieke, B. Polymerization of styrene in microemulsion using gemini surfactants with hydrophilic and hydrophobic spacer groups. Berichte der Bunsengesellschaft fur physikalische Chemie 1998, 102, 1705-1709.

30. Umbach, W. The importance of colloid chemistry in industrial practice. Progr. Colloid Polym. Sci. 1998, 111, 9-16.

31. Schueller, R.; Romanowski, P. The science of reactive hair-care products. Cosmet. Toiletries 1998, 113, 39-44.

32. Kwetkat, K. Gemini surfactants-Applications in real life. In Proceedings of CESIO 5th World Surfactant Congress, Firenze, Italy, 29 May-2 June, 2000; Volume 2, pp. 1094-1096.

33. Lorant, R.; Lahousse, F. Cosmetic composition comprising a gemini surfactant and high levels of solid fatty substance. WO 2013057118A2, 25 April 2013. 
34. Villa, C.; Baldassari, S.; Martino, D.F.C.; Spinella, A.; Caponetti E. Green synthesis, molecular characterization and associative behavior of some gemini surfactants without a spacer group. Materials 2013, 6, 1506-1519.

35. Schmitz, A. Novel betaine derivatives and hair washing preparation containing them. U.K. Patent 1149140(A), 10 October 1967.

36. Dahanayake, M.; Li, J.; Reierson, R.L.; Tracy, D.J. Amphoteric Surfactants having Multiple Hydrophobic and Hydrophilic Groups. U.S. Patent 5656586 A, 12 August 1997.

37. Puchta, R.; Krings, P.; Sandkuhler, P. A new generation of softeners. Tenside Surfactants Deterg. 1993, 30, 186-191.

38. Okano, T.; Fukuda, M.; Tanabe, J.; Ono, M.; Akabane, Y.; Takahashi, H.; Egawa, N.; Sakotani, T.; Kanao, H.; Yoneyanna, Y. Detergent Composition Having Low Skin Irritability. U.S. Patent 5681803, 28 October 1997.

39. Tracy, D.J.; Li, R.; Yang, J. Anionic surfactants having multiple hydrophobic and hydrophilic groups. U.S. Patent 5789371, 4 August 1998.

40. Raths, H.-C.; Biermann, M.; Maurer, K.H. Deodorizing Formulation. U.S. Patent 6277359 B1, 21 August 2001.

41. Rosen, M.J.; Tracy, D.J. Gemini surfactants. J. Surfact. Deterg. 1998, 1, 547-554.

42. Li, R.; Tracy, D.J. Anionic Gemini Surfactants and Methods for Their Preparation. U.S. Patent 5952290A, 14 September 1999.

43. Diz, M.; Manresa, A.; Pinazo, A.; Erra, P.; Infante, M.R. Synthesis, surface active properties and 302 antimicrobial activity of new bis quaternary ammonium compounds. J. Chem. Soc. Perkin Trans. 1994, 2, 1871-1879.

44. Kim, T.S.; Kida, T.; Nakatsuji, Y.; Hirao, T.; Ikeda, I. Surface active properties of novel cationic surfactants with two alkyl chains and two ammonium groups. J. Am. Oil Chem. Soc. 1996, 73, 907-912.

45. Pavlikova, M.; Lacko, I.; Devinsky, F.; Mlynarcik, D. Quantitative relationships between structure, aggregation properties and antimicrobial activity of quaternary ammonium bolaamphiphiles. Collect. Czech. Chem. Commun. 1995, 60, 1213-1228.

46. Pinazo, A.; Diz, M.; Solans, C.; Erra, P.; Infante, M.R. Synthesis and properties of cationic surfactants containing a disulphide bond. J. Am. Oil Chem. Soc. 1993, 70, 37-42.

47. Piera, E.; Infante, M.R.; Clapes, P. Chemoenzymatic synthesis of arginine based gemini surfactants. Biotechnol. Bioeng. 2000, 70, 323-331.

48. Perez, L.; Torres, J.L.; Manresa, A.; Solans, C.; Infante, M.R. Synthesis, aggregation, and biological properties of a new class of gemini cationic amphiphilic compounds from arginine, bis(Args). Langmuir 1996, 12, 5296-5301.

49. Holmberg, K. Natural surfactants. Curr. Opin. Colloid Interface Sci. 2001, 6, 148-159.

50. Infante, M.R.; Pinazo, A.; Seguer, J. Non-conventional surfactants from amino acids and glycolipids: Structure, preparation and properties. Colloids Surf. A Physicochem. Eng. Asp. 1997, 49-70.

51. Yoshimura, T.; Sakato, A.; Esumi, K. Solution properties and emulsification properties of amino acid-based gemini surfactants derived from cysteine. J. Oleo Sci. 2013, 62, 579-586. 
52. Masuyama, A.; Endo, C.; Takeda, S.; Nojima, M. Ozone-cleavable gemini surfactants, a new candidate for an environmentally friendly surfactant. Chem. Commun. 1998, 18, 2023-2024.

53. Masuyama, A.; Endo, C.; Takeda, S.Y.; Nojima, M.; Ono, D.; Takeda, T. Ozone-cleavable gemini surfactants. Their surface-active properties, ozonolysis, and biodegradability. Langmuir 2000, 16, 368-373.

54. Tatsumi, T.; Zhang, W.; Kida, T.; Nakatsuji, Y.; Ono, D.; Takeda, T.; Ikeda, I. Novel hydrolyzable and biodegradable cationic gemini surfactants: 1,3-bis[(acyloxyalkyl)-dimethylammonio]-2hydroxypropane dichloride. J. Surfact. Deterg. 2000, 3, 167-172.

55. Perez, L.; García, T.; Ribosa, I.; Vinardell, P.; Manresa, A.; Infante, M.R. Biological properties of arginine-based gemini cationic surfactants. Environ. Toxicol. Chem. 2002, 21, 1279-1285.

56. Li, J.; Dahanayake, M.; Reierson, R.L.; Tracy, D.J. Amphoteric surfactants having multiple hydrophobic and hydrophilic groups. U.S. Patent 5914310, 22 June 1999.

57. O’Lenick, A.J.; O’Lenick, K.A. Surfactants Based upon Alkyl Polyglycosides. U.S. Patent 6627612, 30 September 2003.

58. Zoller, U.; Sosis, P. Handbook of Detergents, Part F: Production (Surfactant Science); CRC Press: Boca Raton, FL, USA, 2008.

(C) 2013 by the authors; licensee MDPI, Basel, Switzerland. This article is an open access article distributed under the terms and conditions of the Creative Commons Attribution license (http://creativecommons.org/licenses/by/3.0/). 